\title{
Speed as a New Dimension of Globalization
}

Hauer $\mathbf{T}^{*}$

Department of Pedagogical Studies, University of Zilina, Zilina, Slovakia

*Corresponding author: Hauer T, Department of Pedagogical Studies, University of Zilina, Univerzitna 8215/1, 010 26 Zilina, Slovakia, Tel: +4215131453; E-mail: thauer777@gmail.com

Received date: May 20, 2016; Accepted date: June 07, 2016; Published date: June 13, 2016

Copyright: (c) 2016 Hauer T. This is an open-access article distributed under the terms of the Creative Commons Attribution License, which permits unrestricted use, distribution, and reproduction in any medium, provided the original author and source are credited.

\begin{abstract}
According to Virilio, changes in society (hence globalization as well) can be monitored from the perspective of speed. From this point of view, it is also possible to explain the development of the society as a dromocratic development. In this case, we find that during a certain recent historical interval there was a fundamental event, which resulted in unusual acceleration in all areas of the society, and within the two centuries, the speed of some human activities reached its limit, the speed of light - for the first time in the history. Virilio thinks that in reality, there is no industrial revolution, but only dromocratic-speed revolution, there is any democracy, but dromocracy. Which means that by using terms such as the "industrial revolution", "technological progress", or globalization of modern thinking collectively refers only to the various striking phenomena, but the essential, less prominent issue eludesnamely, speeds. What characterizes the current form of globalization is an unstable mixture of fast information and slow movements, fast technology and slow society of technocratic liberalism. Besides monetary wealth standard, there is a globalized standard of the speed limit.
\end{abstract}

Keywords: Speed; Dromology; Globalization; Wealth; Accelerating

\section{Introduction}

To say today that speed is obsolete is an untruth as obvious as that which consists in praising slowness [1]. At the beginning of human history, there was only slowness-slowness of life of agricultural society. Speed was created by people-merchants, soldiers, industrialists, scientists, engineers, computer scientists, bankers, etc. The present-day Identification with the speed may lead us to many different conclusions. The speed of our world is full of contradictions; the accelerated world conceals quite a few paradoxes. Most speed phenomena seem reasonable at first glance and usually it is actually the case. This applies particularly to those devices and equipment that we use every day from cars and Velcro over Fast Food and email, to our computer and particle accelerators. Their formation is understood as a response to the clearly defined need, their further development as a useful improvement. In today's life, it is only speed that counts, and nothing else. The question how much speed one needs and what rate of acceleration is tolerable for the economy, society and environment, remains unanswered. Speed began to gain positive value in the late 19th century. Dromology by Virilio [1] seeks to analyze the ways that were crucial for the development of speed. He asks how the principle of acceleration in Central and Western Europe arose and explains the origin and method of spreading "various triggers of speed". Virilio's theory shows the far-reaching extent to which the speed conquered all and everything over the centuries: transportation and production, peace and war, men and women, urban and rural areas, work and leisure time, arts and commerce. Virilio [1] clearly shows us how the principle of acceleration of the word has taken root in professional and private lives of individuals and societies in both good and bad sense, and how it has changed and continues changing our standards, values, perceptions and mentality.
The development of high technical speeds would thus result in the disappearance of consciousness as the direct perception of phenomena that inform us of our own existence. Cinema is not a seventh art but an art that combines all of the others: drawing, painting, architecture, music, but also mechanical, electrical works, etc., [1]. Dromological research by Virilio [2] present a critical analysis of the consequences for our perception and logistics caused by polar inertia, inertia of absolute speed. Speed changes the field of our perception because it transforms the habitual understanding of ontological characteristic of reality, i.e., time and space. Speed treats vision like its basic element; with acceleration, to travel is like filming, not so much producing images as new mnemonic traces, unlikely, supernatural. In such a context death it can no longer be felt as mortal; it becomes, as in William Burroughs, a simple technical accident, the final separation of the sound from the picture track [1]. What is much more important for Virilio's concept of aesthetics of disappearance is the role of unconscious disappearing of objects from our field of perception, aesthetics of disappearing, one of the consequences of dromology, is based on studying cinematographic effects coming from the area of art, film, television and video. What is given to see is due to the phenomena of acceleration and deceleration in every respect identifiable with intensities of light [1].

\section{Political Economy of Speed and Globalization}

It is certainly very difficult to define the concept of globalization precisely. Upon closer examination of the concept itself, however, we find that there are basically two methodological approaches to define the whole process. The first methodological approach equates globalization with integration, the second methodological direction views the phenomenon of globalization as a completely new qualitative change, the correct understanding and interpretation of which is in direct proportion to considering those new variables. The new phenomena also include speed, which occupies the forefront position; a French theorist and cultural critic Virilio [3] attempts to categorize the theories of speed (dromology) within the context of social sciences 
and humanities. In defining the term of globalization, but also in defining the process and the concept of integration, we are confronted with different definitions. Integration can be defined in various ways. In professional literature, we encounter the concept of integration at macroeconomic and microeconomic level. The first level is a more functional approach that characterizes the interconnection of enterprise systems. The second level indicates a process of gradual cross-linking, alignment and convergence of the various national economies. However, there is also a definition of geographic integration. Integration undoubtedly contributes to the internationalization of the world economy itself that is the situation when various forms of economic activity exceed the national economy of each country [4]. It is therefore clear that in the definition of globalization in the integration concept, there are many different forms of interpretation. Some authors talk about integration at the level of markets in goods, services, human capital and technology. Other authors consider integration as a purely geographic concept, monitoring the growing dependence of individual countries. However, sometimes globalization is identified with integration without any further explanation.

Globalization followed within the context of deregulation in the world economy [5]. Market liberalization came first and led to an unprecedented expansion of international trade, which began in the mid-1950s. Liberalization of regimes for foreign investment came next, and led to a wave of international investment that began at the end of the 1960s. Financial liberalization came last. Internationalization of finance in the mid-1980s followed after that. The technological revolution in transport and communications, which is connected with the transmission of information and computer technology that makes it easier to process information, has created information technology, which is extraordinary in speed and range. This technological development removed geographic barriers. Some authors [6], also refer to technological development. They consider it crucial. Globalization is then directly conditioned by the development of technologies, and it would have been unthinkable without specific direction of the current technical development and scientific progress. The result is a more efficient functioning of market systems, faster economic integration, deepening interdependence, i.e., the mutual political and economic dependence of the national economies and the interconnections of economic activities in the areas of trade, finance and investment. The result is a further backward support for globalization processes. Scientific and technological progress leads to facilitating the interconnection of world markets, thus also increasing the possibilities for international trade.

Globalization is a spontaneous, uncontrolled process [4]. To a certain extent, it leads to mutual integration of some companies at the higher, global level. Ulrich Beck describes globalization as "a certain most frequently used-misused-least often defined, probably the worst understood, the most vague, and politically the most effective slogan of the past, but also of the upcoming years" [7]. Globalization has become a unifying concept of academic and general intellectual debates of the 1990s (while it gradually eclipsed the postmodern discourse), as well as an object of parliamentary debates, management meetings, and numerous activist campaigns. Globalization has been criticized as well as celebrated; it is associated with hopes and fears, often simultaneously. Some lobby for globalization, others demonstrate and fight against it. All these phenomena make it an empirical fact, even though this fact should be of the nature of the theorem, according to which everything becomes real, what people consider real. If we consider the genesis of this concept and the reasons for which it came to the forefront of scientific and media popularity, one cannot fail to notice the coincidence in time between the boom of the globalization discourse and the end of the second millennium. It is true that "all European generations from the early 19th century had felt that they were experiencing an unprecedented era" [8], but the proximity of the magical year with three zeroes made this feeling even stronger and duly globalized. In the invocation of globalization, it is possible to recognize chiliastic hidden motive associated with the idea that in the upcoming period, certain predictions (historical trends) will be fulfilled, pushing human history into an entirely new dimension. The term globalization now often plays the same role as the MarxistLeninist concept of historical necessity in the past. The future holds its final form, which reveals itself in history, and that is a global market, global government, and global civil society.

The concept presented so far has been focused almost exclusively on the area of economic globalization. The sphere of culture, although it is "one of the most immediately perceived and experienced forms of globalization" [9], is surprisingly often omitted in these debates, which leads to the fact that the meaning of the term globalization is reduced to just the processes of political and economic changes. If we, however, view globalization not only as a process of deepening the interdependence of macro-structural phenomena, but also as a process of global exchange of symbols and symbolic systems-a myth, values [10], and behavior patterns-which are involved in the reconfiguration of personal and collective identities, the cultural sphere must be given equal if not more attention than economy and politics, with which it is, after all, directly related. Dominant carriers of cultural representations in the modern society including its globalized phase are the communication media [11], machines driving the lighting effects and working at the limit speed of light. Logically, now they have become one of the main symbols of technological and cultural globalization. Now they are carriers of speed and radical changes [12].

\section{Conclusion}

The concept of globalization has become the subject of theoretical thinking in the late $80 \mathrm{~s}$ and 90 s of the twentieth century and it is considered a phenomenon that will be used throughout the third millennium in the world economy. The essence of the modern era can be described using the concepts of wealth and speed. The current social, philosophical and economic theories only cope with the analysis of the concept of wealth. The theme of speed and acceleration has remained completely outside their field of vision. Economic and social sciences and philosophy are able to convey a lot of about wealth, but until recently, they have not been able to tell almost anything about speed. The problem of speed has a more prominent place in economic and social sciences. However, without the fact of accelerating, it is not possible to imagine and theoretically grasp the modern era at all. The absence of problems of speed and acceleration in economic and social sciences is perplexing because the speed of our modern societies has become one of the highest values and one of the most important requirements of the present time. The notion of speed does not yet have a clear and usable definition, and it lacks systematic economic and social analysis. It seems, therefore, that it is necessary to complement the existing theoretical reflection on the concept of globalization with another important fact, namely, the concept of speed. Speed is a key analytical tool for exploring hitherto neglected dromologic dimension of globalization. The main paper's aim is the analysis of new political economy of speed and its relation to the globalization. 


\section{References}

1. Virilio P (1991) The aesthetitics of disappearance. Semiotext(e), New York.

2. Virilio P (1986) Speed and Politics. Semiotext(e), New York.

3. Virilio P (1999) Politics of the Very Worst. Semiotext(e), New York.

4. Cohen TH (2016) Global Political Economy. Routledge, Taylor and Francis Group, London and New York.

5. Albrow M (1996) The global age: State and society beyond modernity. Polity Press, Cambridge.

6. Gilpin R (2001) Global political economy: Understanding the International Economic Order, Princeton University Press.
7. Beck U (1997) Was ist Globalisierung?-Suhrkamp.

8. Gubová O (2014) Several Remarks on the theory of Regionalism and Interregionalism. ICEI 2014. 2nd International Conference on European Integration, Ostrava pp: 469-476.

9. David H (2000) A Globalizing World? Culture, Economics, Politics. Routledge, London and New York.

10. Feber J (2015) Autonomous and Heteronomous Morality in Social Acting. SGEM, Bulgaria pp: 527-532.

11. Barker C (1999) Television, Globalization and Cultural Identities. Open University Press, Buckingham, Philadelphia.

12. Armitage J (2000) From Modernism to Hypermodernism and Beyond. Sage Publications, London. 